\title{
Trade of Permits for Greenhouse Gas Emissions; Bilateral Trade Need not Be the Answer
}

\author{
Roberto Burguet \\ Institute for Economic Analysis (CSIC) \\ JAUME SEMPERE \\ El Colegio de México
}

This draft: May 2007

\begin{abstract}
The Kyoto Protocol sets national quotas on $\mathrm{CO}_{2}$ emissions and allows international trade of these quotas. We argue that this trade is characterized by asymmetric, identity-dependent externalities, and show that bilateral trade may not be sufficient for an efficient allocation of emissions. We derive conditions under which bilateral trade does improve the allocation of permits. The conditions are strong. In this sense, we argue that, for emissions permits, market design matters.
\end{abstract}

J.E.L. Classification Numbers: D62, F18,

Keywords: Terms of trade, asymmetric externalities, permits trade

Mailing address: Institute for Economic Analysis

Campus UAB; 08193-Bellaterra; Barcelona (Spain)

e-mail: roberto.burguet@iae.csic.es; jsempe@colmex.mx

Acknowledgements: We thank Dragan Filipovich and Marcelo Soto for helpful comments. Burguet acknowledges financial support of the Spanish Ministry of Education and Science, grant SEC2002-02506. 


\section{Introduction}

In 1997, at the Climate Change Summit in Kyoto, 39 countries agreed to reduce their greenhouse gas emissions during the five year period 2008-2012. The agreement prescribed binding targets for each country while allowing international trade of these quotas. Given the location-independent effects of emissions, the possibility of trade has been welcomed as a key feature of the agreement which will guarantee that the Kyoto goals are attained at minimum cost.

Implicit in this optimism is the assumption that "market forces", if free to act, will induce cost efficiency. If the initial allocation of quotas does not minimize the cost of emissions, countries will gain from trading (part of their) quotas. Thus, the possibility of trade means that, for efficiency purposes, the initial allocation of quotas does not matter. ${ }^{1}$ The experience with the 1990 U.S. Acid Rain Program reinforces this view. Within this program, $\mathrm{SO}_{2}$ emission permits were initially allocated in proportion to historical emissions, but permits were tradable. According to most assessments, indeed bilateral trade was successful in leading to an efficient allocation of emissions. ${ }^{2}$

In a recent paper, Copeland and Taylor (2005) have argued that there is an important difference between permit trade in a closed economy (e.g., the U.S. $\mathrm{SO}_{2}$ experience) and permit trade in an open, international setting (e.g., $\mathrm{CO}_{2}$ permit trade): In the latter, trade in permits has terms-of-trade effects. That is, when a country trades in emission permits, and so varies its

\footnotetext{
${ }^{1}$ Distributional effects are obviously recognized.

${ }^{2}$ See, for instance, Schmalensee et al., 1998, or Joskow et al. (1998).
} 
emissions quota, it changes its supply of commodities to the world market and this can affect international prices. ${ }^{3}$

In this paper, we build on this insight and note that these effects constitute an externality that trading parties impose on third countries. Moreover, terms-of-trade effects depend on the identity of the trading parties and affect different countries differently, depending on their respective position in international commodities markets. Thus, terms-of-trade externalities associated to trade in emissions permits are asymmetric and identity dependent.

There is a literature on auction and mechanism design that looks at the consequences of this type of externalities. (See, for instance, Jehiel and Moldovanu (1996), (1999), and (2000), or Jehiel, Moldovanu, and Stacchetti (1996).) One of the key lessons of this literature is that under asymmetric, identity-dependent, external effects the willingness to pay for a good (emission quota or permit) can be computed only in equilibrium. Therefore, a simple reference to price taking behavior will not confer an unambiguous meaning to the concept of competitive price. Efficiency becomes then a more difficult target.

These lessons apply directly to the model of Copeland and Taylor once we abandon their assumption that traders in the market for permits are small

\footnotetext{
${ }^{3}$ One consequence is that some economies may end up worse-off after trading in permits despite production efficiency gains. Copeland and Taylor even show cases in which both parties exchanging quotas could be made worse off by this trade. Also, based on the results on the equivalence between trade in goods and trade in factors, they conclude that, for some economies, free trade in goods will make the rule for allocating initial quotas irrelevant for efficiency.
} 
firms. That is what we do in this paper. We assume that governments (that is, large players) can determine permit trade. Thus, we analyze a model where a country's acquisition (and usage) of additional permits affects its domestic welfare as well as the welfare of all other countries. We show that in general bilateral trade will not guarantee that the allocation of permits will move towards efficiency.

We think that the assumption that governments will determine the trade of permits is justified for the case of $\mathrm{CO}_{2}$ emissions that motivates this paper. Indeed, the Kyoto agreement assigns quotas to countries and allows, but does not organize, trade. For instance, there are no provision against governments' regulations that may effectively determine the pattern of permit trade of local firms. And more importantly, the agreement does not attempt to organize a (firm level, globally open) market for permits (along the lines of the European Union Greenhouse Gas Emission Trading Scheme, for instance). ${ }^{4}$

We characterize efficient allocations of permits, and identify conditions on the initial allocation of permits that guarantee that incentives to trade are aligned with efficiency. These conditions are restrictive. In particular, they require that no country is completely specialized in producing clean commodities. Therefore, efficiency is too demanding a target for completely unregulated bilateral trade of emission permits. Our conclusion is that market design for permit trade, and not just bilateral trade, is needed in order

\footnotetext{
${ }^{4}$ Governments in the EU can still affect trade of permits, through their decisions on the amount of permits allocated to their firms, and on what sectors are regulated through permits and what sectors are regulated using other instruments. Thus, the market would have to specify what are the potential users of the permits.
} 
to guarantee efficient allocation of emission rights.

In the next section, we present the model and discuss the externalities generated by bilateral trade in permits via terms-of-trade effects. Then, in Section 3, we show how bilateral trade does not necessarily improve the allocation of permits. We give conditions that guarantee that efficiency of bilateral trade. Section 4 puts these conditions in terms of patterns of output and commodity trade across countries. These two sections contain our main results, most of which are proved in the appendix. Some concluding remarks close the paper.

\section{The model}

Following Copeland and Taylor (2005), we model international trade and the environment in a Heckscher-Ohlin setup. ${ }^{5}$ There are $n$ countries in a two good, two factor world. Trade in commodities is assumed to be free among all countries. We denote output of each of the goods by $X$ and $Y$ respectively. The two factors are human capital, $h$, and pollution, $z$. Different countries have different endowments of human capital, which is inelastically supplied. Thus, we treat pollution as an input (as well as a global externality) and also model differences in human capital endowments as the only fundamental difference across countries.

A quota on pollution is fixed for each country by an international agreement. Denote by $z_{j}$ the quota on pollution fixed to country $j$. All coun-

\footnotetext{
${ }^{5}$ We present a sketch of the model. For a full treatment and motivation, see Copeland and Taylor (2005).
} 
tries are constrained by the international agreement, so global emissions, $Z=\sum_{j} z_{j}$, and their direct effect on the utility of consumers are exogenously fixed. ${ }^{6}$ Without loss of generality, we assume that $h_{1} / z_{1}>h_{2} / z_{2}>$ $\ldots>h_{n} / z_{n}$. We will study countries' incentives to increase their quota by purchasing (part of) other country's quota.

We assume the same technology for all countries, represented by

$$
X_{j}=f\left(h_{j}^{x}, z_{j}^{x}\right)
$$

and

$$
Y_{j}=g\left(h_{j}^{y}, z_{j}^{y}\right),
$$

where $h_{j}^{T}$ and $z_{j}^{T}$ are human capital and pollution allocated to industry $T=$ $X, Y$ located in country $j=1,2, \ldots, n$.

Both $f$ and $g$ are assumed to be strictly concave, and characterized by constant returns to scale. They are increasing in both arguments. Assume that $X$ is more pollution intensive than $Y$. So, from now on, we call $X$ the dirty commodity. Also assume that $Y$ is the numeraire commodity and denote the international price of $X$ by $p$.

With our assumptions, the profit maximizing behavior of price-taking firms can be summarized by the maximization of national income. ${ }^{7}$ That is,

\footnotetext{
${ }^{6}$ Copeland and Taylor (2005) assume that some countries may not be constrained, and study the incentives of these countries to reduce emissions that derive from the trade of permits.

${ }^{7}$ See, for instance, Dixit and Norman (1980), or Wong (1995), pp.40-50 for a recent text-book discusion.
} 
firms' behavior in each country $j$ can be obtained as the solution to

$$
\begin{aligned}
& \operatorname{Max}_{\left\{h_{j}^{x}, h_{j}^{y}, z_{j}^{x}, z_{j}^{y}\right\}} p X_{j}+Y_{j} \\
\text { s.t. } \quad X_{j}= & f\left(h_{j}^{x}, z_{j}^{x}\right), Y_{j}=g\left(h_{j}^{y}, z_{j}^{y}\right), \\
z_{j}= & z_{j}^{x}+z_{j}^{y}, h_{j}=h_{j}^{x}+h_{j}^{y} .
\end{aligned}
$$

Let $G_{j}\left(p, h_{j}, z_{j}\right)$ be the maximum of the above program, which then represents the national income function. Following Copeland and Taylor, we make the implicit assumption that the targeted level of pollution inside a country is attained efficiently.

The demand side is given by a representative consumer in each country $j$ with utility function

$$
U_{j}=U\left(x_{j}, y_{j}\right)
$$

where $x_{j}$ and $y_{j}$ are, respectively, consumption of the dirty and clean commodities by the representative consumer of country $j$. We assume that $U$ is (the same for all countries and) homothetic, strictly increasing in its arguments, and strictly quasi-concave ${ }^{8}$. We also assume that both goods are essential in consumption.

Given homotheticity of preferences (and given that $Z$ is assumed to be constant), the indirect utility of the representative consumer in country $j$ can be written as $V_{j}=I_{j} / \Phi(p)$ where, $I_{j}$ is national income in $j$ (which in equilibrium will coincide with $\left.G_{j}\right)$, and $\Phi(p)$ is the true price index for the

\footnotetext{
${ }^{8}$ Again, the utility may depend on $Z$. However, given our assumption that global pollution $Z$ is exogenously fixed by an agreement, we may disregard this environmental externality.
} 
private goods ${ }^{9}$. Finally, denote the net imports of $X$ by country $j$ by $m_{j}$.

Welfare of a country $j$ is given by the indirect utility of its representative consumer. Then we can compute the gross change in country $j$ 's welfare induced by an increase in its quota as

$$
v_{j} \equiv d V_{j} / d z_{j}=\frac{1}{\Phi(p)^{2}}\left[\Phi(p)\left(\frac{\partial G_{j}}{\partial z_{j}}+\frac{\partial G_{j}}{\partial p} \frac{\partial p}{\partial z_{j}}\right)-G_{j} \frac{\partial \Phi(p)}{\partial p} \frac{\partial p}{\partial z_{j}}\right]
$$

Now, $\frac{\partial G_{j}}{\partial p}=X_{j}$ (see, for instance Wong, 1995, p. 44), and applying Roy's identity (and noticing that $\frac{1}{\Phi(p)}$ is the marginal utility of income), we have that

$$
\frac{1}{\Phi(p)^{2}}\left[-G_{j} \frac{\partial \Phi(p)}{\partial p}\right]=-\frac{1}{\Phi(p)} x_{j}
$$

where the left hand side is the derivative of the indirect utility function with respect to price, taking income as given, and the right hand side is the negative of demand times the marginal utility of income. Thus, we have ${ }^{10}$

$$
v_{j}=d V_{j} / d z_{j}=\frac{1}{\Phi(p)}\left(\frac{\partial G_{j}}{\partial z_{j}}-m_{j} \frac{\partial p}{\partial z_{j}}\right) .
$$

As equation (1) shows, $v_{j}$ can be decomposed in a direct effect on welfare, due to the increase in inputs, and an indirect effect, due to the effect on international terms-of-trade. ${ }^{11}$

\footnotetext{
${ }^{9}$ For instance, if preferences are represented by a Cobb-Douglas $U(x, y)=x^{a} y^{1-a}$ with income $M$ then the indirect utility function is $V=\frac{M}{a^{-a}(1-a)^{a-1} p^{a}}$. So $\Phi(p)=a^{-a}(1-$ a) ${ }^{a-1} p^{a}$.

${ }^{10}$ We should also include the effect on international prices of the change in demand associated to any transfer of income from buyer to seller. However, given our assumptions on utility functions, this change in total demand in international markets is absent.

${ }^{11}$ Notice that this expresion coincides with (23) in Copeland and Taylor (2005), partic-
} 
One could be tempted to argue that $v_{j}$ represents the willingness to pay of country $j$ for a (marginal) increase in its emissions quota. That would be certainly the case if all countries were small, and then all price effects $\frac{\partial p}{\partial z_{j}}=0$. Then, free market forces should lead to trade in permits where the country that is willing to pay the highest price $v_{j}=\frac{\partial G_{j}}{\partial z_{j}}$ buys emissions rights from other countries. However, when countries are not small, the change in quota of country $j$ has effects on other countries as well. Indeed, if country $j$ acquires an additional unit of emission permits, this country will change its output and therefore will change the international terms-of-trade. Indeed, this increase in country $j$ 's quota will have an effect on country l's welfare, $l \neq j$, given by

$$
-e_{l}(j) \equiv d V_{l} / d z_{j}=\frac{1}{\Phi(p)}\left(-m_{l} \frac{\partial p}{\partial z_{j}}\right)
$$

Notice that this indirect effect may be asymmetric across countries since it depends on the net imports of the dirty commodity of the country involved. It is also identity-dependent because it may depend on the identity of the country acquiring the pollution rights. Again, if countries took international prices as given, then all price effects would disappear: $e_{l}(j)=0$.

Before we proceed with the analysis of the consequences of trade for efficiency, notice that, if we define $e_{j}(j) \equiv \frac{1}{\Phi(p)}\left(-m_{j} \frac{\partial p}{\partial z_{j}}\right)$, then

$$
\sum_{l} e_{l}(j)=\frac{1}{\Phi(p)} \frac{\partial p}{\partial z_{j}} \sum_{l} m_{l}=0
$$

since the sum of the net imports is always zero. Also, the following remarks, that we do not need to prove, will be useful later on:

ularized to the case where $Z$ is constant and we do not take into account the possible price paid for the permit. 
Remark 1: If country $j$ is completely specialized in commodity $Y(X)$, then country $l$ is also specialized in that commodity for all $l(>)<j$.

Remark 2: If country $j$ 's imports of commodity $X$ are positive (negative), then country l's imports are also positive (negative) for all $l(>)<j$.

\section{Bilateral Trade and Efficiency}

We now turn to analyzing the relationship between efficiency and the incentives to trade emission permits. If an allocation of permits is (globally) efficient, then a marginal redistribution of permits between any two countries must have a net zero effect on global welfare. Note that $e_{j}(i)$ is the effect of an increase in country $i$ 's permits on country $j$ 's welfare. Thus, the effect of a (marginal) increase in the permits of country $i$ on total welfare is $v_{i}-\sum_{j \neq i} e_{j}(i)=\frac{\partial G_{i}}{\partial z_{i}}$. Thus, a condition for an (interior) efficient allocation of quotas is that $\frac{\partial G_{i}}{\partial z_{i}}$ is the same for all countries. In fact, given our convexity assumptions, this is a sufficient condition for efficiency.

Since preferences are identical and homothetic, and technologies are also identical and homogeneous, if country $j$ is not specialized in any of the commodities then $\frac{\partial G_{j}}{\partial z_{j}}=\frac{\partial g\left(1, \frac{z_{j}^{y}}{h_{j}^{y}}\right)}{\partial z}=P \frac{\partial f\left(1, \frac{z_{j}^{x}}{h_{j}^{x}}\right)}{\partial z}$. Thus, if no country is completely specialized and, by the Factor-Price Equalization Theorem, all countries use the same ratio $\frac{z^{i}}{h^{i}}$, for $i=x, y$, then the allocation of permits is efficient. Moreover, bilateral trade will not take place, since $\frac{\partial p}{\partial z_{j}}$, and then $v_{j}$, is also 
the same for all countries. ${ }^{12}$

That bilateral trade do not destabilize efficient allocations of permits is reassuring. Nevertheless, the real question is whether bilateral trade is enough to guarantee that efficiency will be attained starting from a non efficient position. Or put in less ambitious terms, ${ }^{13}$ if some of them are specialized in the production of one on the commodities, will countries have incentives to trade towards more efficient allocations of permits?

To illustrate the answers that we will give to this question, consider the following example:

Example: There are three countries with Cobb-Douglas preferences and technologies:

$$
U\left(x_{j}, y_{j}\right)=x_{j} y_{j}
$$

and

$$
X_{j}=\left(h_{j}^{x}\right)^{\frac{1}{3}}\left(z_{j}^{x}\right)^{\frac{2}{3}}, Y_{j}=\left(h_{j}^{y}\right)^{\frac{2}{3}}\left(z_{j}^{y}\right)^{\frac{1}{3}} .
$$

Let the initial allocation be $\left(z_{1}, h_{1}\right)=(.6,3),\left(z_{2}, h_{2}\right)=(1,2)$, and $\left(z_{3}, h_{3}\right)=$ $(1.5,1)$. With these values, country 1 specializes in the clean commodity $Y$, and country 3 specializes in the dirty commodity $X$, whereas country 2

\footnotetext{
${ }^{12}$ In this case, Copeland and Taylor argue that any rule for asigning emission permits is efficient.

${ }^{13}$ Indeed, political economy constraints may limit the amount of permits each one country can consider trading. Also, we are considering "emissions" as an input. In reality, what is an input is not the emissions per se, but other goods used in production that are associated to emissions. If some of these are not tradable, then emissions permits may be only partially tradable. However, all we need for the analysis below is that "some" permits are tradable.
} 
produces both commodities, but exports the dirty commodity. ${ }^{14}$

We can compute $\phi \mathbf{v}$ and $\phi \mathbf{e}$ and obtain $\phi \mathbf{v}=(.88, .85, .67)$, and $\phi e_{1}(2)=$ $-.24, \phi e_{1}(3)=-.07, \phi e_{2}(1)=-.005, \phi e_{2}(3)=.005, \phi e_{3}(1)=-.09$, and $\phi e_{3}(2)=.23$. With these values, $\phi\left[v_{i}-\sum_{j \neq i} e_{j}(i)\right]$ is $1.02, .86$, and .745 respectively for $i=1,2$, and 3 . Thus, any trade where country 1 sells permits is a trade away from efficiency. Also, any trade where country 2 sells to country 3. However, notice that country 1 would be willing to sell permits to country 2 at any price above $v_{1}+e_{1}(2)=.64 / \phi$, and country 2 would be willing to pay up to $v_{2}+e_{2}(1)=.84 / \phi$ to get the permit from country 1. Thus, bilateral trade may take the allocation even further away from efficiency (and impose a welfare loss).

This is not the only possible trade at mutual advantage in this example. In fact, country 3 is willing to sell permits to country 1 at a price that country 1 is willing to accept, and this trade is efficient. Also, country 2 is willing to sell to country 3 at a price that country 3 is willing to accept, and this trade is also inefficient. What trade would take place is a question that would need a richer model to answer, but what the example illustrate is that bilateral trade alone does not guarantee that the efficient trade will take place.

The example also illustrates the consequences of external effects associated to bilateral trade. Indeed, when countries 1 and 2 trade, they do not consider that this trade has a net, negative effect on country 3. Indeed, 3's exports are large, and the transfer of permits from country 1 to country

\footnotetext{
${ }^{14}$ With these values, $p=1.27$. Country 1 uses a ratio of $z$ to $h$ of .2 in the production of $Y$, and country 3 uses a ratio $3 / 2$ in the production of $X$, whereas country 2 uses, of course, a ratio between these two number in the production of each commodity.
} 
3 implies a drastic reduction of the price of exports: country 1, which is specialized in clean commodities, reduces its production of clean goods and country 2 increases its production of the dirty commodities, and reduces its own production of the clean commodity (Rybczynski theorem). The termsof-trade effects of such permits exchange on country 3 are represented by the difference between $e_{3}(2)$ and $e_{3}(1)$, which means a worsening of size $.32 / \phi$ on the welfare of country 3 .

Is the example above exotic in any sense? In other words, what conditions guarantee that inefficient trades will not occur? We now aim at answering this question.

For a given allocation of permits, let $I^{*}$ be the set of all solutions to

$$
i^{*}=\arg \max _{i}\left\{v_{i}-\sum_{j \neq i} e_{j}(i)\right\}=\arg \max _{i} \frac{\partial G_{i}}{\partial z_{i}} .
$$

Any trade where $i^{*} \in I^{*}$ sells permits to a country $j \notin I^{*}$ is an inefficient trade. A first step towards answering our question is given by the following lemma.

Lemma 1 The gains from a bilateral trade of permits from some $i^{*} \in I^{*}$ are non positive if

$$
\sum_{l \neq i^{*}, j} e_{l}\left(i^{*}\right) \geq \sum_{l \neq i^{*}, j} e_{l}(j)
$$

for all $j \neq i^{*}$. Also, if this condition is satisfied, there exists a price at which country $j, j \notin I^{*}$, sells to country $i^{*}$ at mutual advantage.

Proof: As in the example, a necessary condition for a trade of quota from country $i^{*}$ to country $j$ is that $v_{j}+e_{j}\left(i^{*}\right)>v_{i^{*}}+e_{i^{*}}(j)$. Indeed, the left 
hand side is the willingness to pay of country $j$ for this bilateral trade, and the right hand side is the minimum ask price for country $i^{*}$. Now, from the definition of $I^{*}, v_{i^{*}}-\sum_{l \neq i^{*}} e_{l}\left(i^{*}\right)>v_{j}-\sum_{l \neq j} e_{l}(j)$ for all $j \notin I^{*}$. Thus, if $\sum_{l \neq i^{*}, j} e_{l}\left(i^{*}\right) \geq \sum_{l \neq i^{*}, j} e_{l}(j)$, summing up these two inequalities we get

$$
v_{i^{*}}-e_{j}\left(i^{*}\right)>v_{j}-e_{i^{*}}(j),
$$

and this proves the first part of the lemma. The proof of the second part follows the same line. QED.

The interpretation of Lemma 1 is intuitive. Countries $i^{*}$ and $j$ will trade without considering the externalities their trade imposes on third countries. That is, the private incentive for trade is equal to the social incentive (the total welfare effects) minus the externalities on third parties. Therefore, when the social incentive and the (negative of) the externalities on third countries are aligned, the private incentive and the social one have the same sign. Thus, trade would be impossible if all the social gains from trade had already been exhausted. Moreover, if social gains from trade had not been exhausted, a trade towards the efficient allocation would also improve the private plight of the parties. We also put this lemma in terms international trade. Recalling that $\sum_{l} e_{l}(j)=0$,

Corollary: No inefficient bilateral trade involving sale of permits by $i^{*} \in$ $I^{*}$ can be at mutual advantage if, for all $j \neq i^{*}$,

$$
\left(m_{i^{*}}+m_{j}\right)\left(\frac{\partial p}{\partial z_{i^{*}}}-\frac{\partial p}{\partial z_{j}}\right) \leq 0 .
$$

Also, if this condition is satisfied, there exists a price at which country $j$, $j \notin I^{*}$, sells to country $i^{*}$ at mutual advantage. 


\section{Trade, Specialization, and the Efficiency of Trade}

Lemma 1 and its corollary show conditions that guarantee some sort of "stability" of the efficient solution. These conditions are set in terms of net trades and the impact of permits on international prices. The latter may be difficult to observe. In this section we relate the conditions in the previous section with the structure of output of the different countries.

From now on, let us denote by $\widehat{i}$ the country with lowest rate $z / h$ (the country most intensive in $h$ ) among the ones that are not specialized ${ }^{15}$. Thus, all countries $j<\widehat{i}$ will produce only the clean commodity $Y$. Moreover, all countries specialized in $Y$ will import commodity $X$, so that $m_{j}>0$ for these countries.

Under constant returns to scale, the productivity of an input in the production of one good depends (inversely) on the ratio of that input to the other(s) in that production. When a country is completely specialized in one commodity, this ratio is simply the ratio of the endowments. With little more than this observation, we can show that

Lemma 2: $1 \in I^{*}$. If $\widehat{i} \neq 1$, then $I^{*}=\{1\}$. If $\widehat{i}=1$, then $I^{*}$ coincides with the set of countries that are not specialized in production.

Proof: See the Appendix.

Lemma 2 is intuitive. If two countries are producing the same good, it is efficient to assign additional permits to the one that is doing so with the

\footnotetext{
${ }^{15}$ There may be extreme cases where all countries are specialized. This is a simple case that follows the same line of analysis.
} 
greatest ratio of $h$ to $z$. For the case of commodity $X$ one of these countries is $\hat{i}$. But for country $\hat{i}$ the slope of the production possibilities frontier is equal to the price. Then, it is almost immediate that countries that face scarcity (relative to the market transformation rate) of the input $z$ should be the ones that are assigned any extra amount of such input. Thus, efficiency requires that this input is assigned to country 1 if this country is completely specialized in $Y$, or else to some country that produces both commodities. The signs of price effects and their relative sizes are also, and for similar reasons, well behaved:

Lemma 3: $\frac{\partial p}{\partial z_{j}}>\frac{\partial p}{\partial z_{j^{\prime}}}>0$ for all $j<j^{\prime}<\widehat{i}$. Also, if country $j>\widehat{i}$ is completely specialized in commodity $X$, then $\frac{\partial p}{\partial z_{i}}<\frac{\partial p}{\partial z_{j^{\prime}}}<0$.

Proof: See the Appendix.

Notice that the effect on the price of $X$ of an increase in emissions permits of country $\hat{i}$ is negative, from Rybczynsky's theorem. A simple corollary of this theorem is that this effect is the same for all countries that produce both goods. In fact, the largest, negative effect on the price is obtained by assigning new emission permits to any of these countries. Lemma 3 is (partly) a consequence of the fact that, under our assumptions on preferences and technologies, consumers in each country spend the same proportion of their income in each of the commodities. Then, each country $j<\widehat{i}$ spends the same proportion of their income in imports (of the dirty commodity), and each country $j$ that is completely specialized in $X$ exports the same proportion of their outcome.

We are now ready to answer our question: what does it take for the conditions of Lemma 1 to be satisfied? The answer is our proposition 1: 
Proposition 1: For $i^{*} \in I^{*},\left(m_{i^{*}}+m_{j}\right)\left(\frac{\partial p}{\partial z_{i^{*}}}-\frac{\partial p}{\partial z_{j}}\right) \leq 0$ for all $j \neq i^{*}$ if and only if $\hat{i}=1$. That is, if and only if country 1 produces both commodities.

Proof: See the Appendix.

The next proposition analyzes conditions such that the gains from trade are not only positive when trade is efficient, but are also maximized by such trade.

Proposition 2: Assume that for $i^{*} \in I^{*},\left(m_{i^{*}}+m_{j}\right)\left(\frac{\partial p}{\partial z_{i^{*}}}-\frac{\partial p}{\partial z_{j}}\right) \leq 0$ for all $j \neq i^{*}$ (and then $\hat{i}=1$ ). For any $j \notin I^{*}$ the gain from trading emission permits with $i^{*}$ is positive and larger that the gain from trading with any other country not in $I^{*}$.

Proof: See the Appendix.

Proposition 1 establishes necessary conditions for Lemma 1 to apply, so that efficient trades of permits are feasible and no trade involving selling permits by their most efficient user is feasible. Yet, as in our example, other permit trades between countries not in $I^{*}$ may be feasible even under the conditions of Proposition 1. We do not know whether those trades would be efficient or not. Would a country sell permits to another not in $I^{*}$, instead of selling to a country in $I^{*}$ ? Again, we would need a full fledged model of how countries find partners, which is beyond the scope of this paper. However, Proposition 2 suggest that reasonable such models would predict the right trade under the conditions of Lemma 1.

Summarizing our results, only when the country with the highest relative endowment of $h$ is not too intensive in $h$ and/or is sufficiently large so as to not specialize in any commodity it is possible to guarantee that bilateral 
trade would lead initial allocations toward more efficient ones. Notice that these conditions are strong. Thus, the initial allocation of rights is likely to influence the final efficiency of the allocation of emissions.

\section{Concluding remarks}

This paper has shown that free market forces, understood as the unregulated, decentralized ability of governments to trade, is not a sufficient condition for an efficient allocation of carbon-dioxide emission quotas. The corollary is that market design, and not just market forces, may be a key ingredient to attain this efficiency goal.

The main feature of permits trade that explains this result is the presence of identity-dependent, asymmetric, external effects. Different countries may have different preferences about who obtains additional permits, if they themselves do not.

There are three assumptions that confer full fledge to our results. The first one is openness of the international commodities market. The second is that the parties trading in the permit market are not "small". Indeed, if they were, even though the aggregate profile of permits would affect an individual country, one can still assume that no individual country can modify it. The third is that parties are not "small" in the commodities market either. If they were, international prices in these markets would not be affected by changes in production of an individual country, and therefore externalities (effects on terms-of-trade) would not be an issue.

In the above analysis we have assumed that countries buy permits only 
to use them, and do not trade for purely speculative reasons. ${ }^{16}$ Also, the results were obtained under several simplifying assumptions (two commodities, symmetry in preferences and technologies,...). However, we think that the arguments made are sufficiently grounded on economic arguments to support the idea that bilateral trade is not a good substitute for the design of a market for permits.

\section{References}

Copeland, B. R., And M. S. TAylor (2005) "Free Trade and Global Warming: A Trade Theory View of the Kyoto Protocol", Journal of Environmental Economics and Management 49, 205-234.

Cramton, P. And S. KerR (1998) "The Distributional Effects of Carbon Regulation: Why Auctioned Carbon Permits are Attractive and Feasible," mimeo U. of Maryland.

Dixit, A., AND V. Norman (1980) Theory of International Trade. Cambridge University Press.

Jehiel, P. And B. Moldovanu (1996) "Strategic Nonparticipation", Rand Journal of Economics, 27(1), 84-98

Jehiel, P. And B. Moldovanu (1999) "Resale Markets and the Assignment of Property Rights", Review of Economic Studies 66(4), 971-991.

\footnotetext{
${ }^{16}$ If countries can buy permits for purely speculative motives, then bilateral trade results in the same final allocation independent of the initial distribution (Jehiel and Moldovanu, 1999) but in general this allocation is not efficient. Therefore bilateral trade would not even be desirable.
} 
Jehiel, P. And B. Moldovanu (2000) "Auctions with Downstream Interaction Among Buyers", Rand Journal of Economics, 31(4), 768-791

Jehiel, P., B. Moldovanu, and E. Stacchetti (1996), "How (Not) to Sell Nuclear Weapons" American Economic Review; 86(4), 814-29

Joscow, P., R. Schmalensee, And E. Bailey (1998), "The Market for Sulfur Dioxide Emissions," American Economic Review 88, 669-685.

Schmalensee, R., P. Joskow, A. Ellerman, J. Montero, and E. Bailey (1998) " "Interim Evaluation of Sulfur Dioxide Emissions Trading, Journal of Economic Perspectives, 12(3), 53-68.

Wong, K-Y. (1995), International Trade in Goods and Factor Mobility, The MIT Press.

\section{Appendix}

Lemma 2: $1 \in I^{*}$. If $\widehat{i} \neq 1$, then $I^{*}=\{1\}$. If $\widehat{i}=1$, then $I^{*}$ coincides with the set of countries that are not specialized in production.

Proof: All countries $i=1, \ldots, \hat{i}-1$ specialize in commodity $Y$. That is, $G_{j}\left(p, h_{j}, z_{j}\right)=g\left(h_{j}, z_{j}\right)$. Thus,

$$
\frac{\partial G_{j}}{\partial z_{j}}=\frac{\partial g\left(1, \frac{z_{j}}{h_{j}}\right)}{\partial z}, \forall j<\widehat{i},
$$

Since $g$ exhibits decreasing returns in each of its inputs, and $\frac{h_{j}}{z_{j}}>\frac{h_{j^{\prime}}}{z_{j^{\prime}}}$ for $j<j^{\prime}$, this excludes $2, \ldots, \hat{i}-1 \in I^{*}$. Similarly, we show $\frac{h_{j}}{z_{j}} \leq \frac{h_{i}^{x}}{\frac{z^{x}}{x^{x}}}$ for all $j$ that specialize in commodity $X$. That is, country $\hat{i}$ produces commodity $X$ using $h$ more intensively than country $j$. Indeed, since $\hat{i}$ produces both 
commodities,

$$
P \cdot \frac{\partial f\left(\frac{h_{i}^{x}}{z_{i}^{x}}, 1\right)}{\partial h}=\frac{\partial g\left(\frac{h^{y}}{z_{i}^{y}}, 1\right)}{\partial h}
$$

Thus, if $\frac{h_{j}}{z_{j}}>\frac{h_{i}^{x}}{z_{i}^{x}}$, then

$$
P \cdot \frac{\partial f\left(\frac{h_{j}}{z_{j}}, 1\right)}{\partial h}<\frac{\partial g\left(\frac{h_{i}^{x}}{\frac{i}{z^{x}}}, 1\right)}{\partial h}
$$

so that country $j$ would increase its national income by switching an infinitesimal amount of inputs from the production of $X$ to the production of $Y$ in the proportion $\frac{h_{i}^{y}}{z^{y}}$.

Now, applying the envelope theorem, $\frac{\partial G_{\hat{i}}}{\partial z_{\hat{i}}}=P \cdot \frac{\partial f\left(h_{i}^{x}, z_{i}^{x}\right)}{\partial z}>P \cdot \frac{\partial f\left(h_{j}, z_{j}\right)}{\partial z}=$ $\frac{\partial G_{j}}{\partial z_{j}}$. This excludes $i^{*}>\widehat{i}$ and specialized in production of $X$. We need only excluding $1<\widehat{i} \in I^{*}$. Notice that $\hat{i} \in I^{*}$ implies that $\frac{h_{i}^{y}}{z_{i}^{y}}>\frac{h_{\hat{i}-1}}{z_{\hat{i}-1}}$, since $\frac{\partial G_{j}}{\partial z_{j}}=\frac{\partial g\left(1, \frac{z_{j}^{y}}{h_{j}^{y}}\right)}{\partial z_{j}}$ for $j \leq \hat{i}$, and $\frac{\partial^{2} g}{\partial z^{2}}<0$. On the other hand, since $\frac{h_{\hat{i}-1}}{z_{\hat{i}-1}}>\frac{h_{\hat{i}}}{z_{\hat{i}}}$ it is immediate that $\frac{h_{i}^{x}}{z_{i}^{x}}<\frac{h_{\hat{i}-1}}{z_{\hat{i}-1}}\left(<\frac{h_{i}^{y}}{z_{\hat{i}}^{y}}\right)$. Also, notice that country $\widehat{i}-1$ could always switch a small amount of inputs $z$ and $h$ in the proportion $\frac{h^{x}}{\frac{i}{z^{x}}}$, without reducing the ratio $\frac{h^{y}}{\frac{i}{z^{y}}}$. Then, since $P \cdot \frac{\partial f\left(\frac{h^{x}}{i}, 1\right)}{\partial z}=\frac{\partial g\left(\frac{i}{z^{x}}, 1\right)}{\partial z}>$ $\frac{\partial g\left(\frac{h \hat{i}-1}{z_{\hat{i}-1}}, 1\right)}{\partial z}$, country $\widehat{i}-1$ 's income would increase, which contradicts one of the equilibrium conditions. Lemma 2 follows.

The last part of the Lemma follows from the observation just proved that $\frac{\partial G_{\widehat{i}}}{\partial z_{\hat{i}}}>\frac{\partial G_{j}}{\partial z_{j}}$, for $j>\widehat{i}$ and specialized in production of $X$, together with the fact (from the factor price equalization theorem) that $\frac{\partial G_{i}}{\partial z_{i}}=\frac{\partial G_{h}}{\partial z_{h}}$ for all $j, h$ that are not completely specialized in production. QED. 
Lemma 3: $\frac{\partial p}{\partial z_{j}}>\frac{\partial p}{\partial z_{j^{\prime}}}>0$ for all $j<j^{\prime}<\widehat{i}$. Also, if country $j>\widehat{i}$ is completely specialized in commodity $X$, then $\frac{\partial p}{\partial z_{i}}<\frac{\partial p}{\partial z_{j^{\prime}}}<0$.

Proof: Consider the market clearing condition

$$
\sum_{l=1}^{n} m_{l}=0
$$

Totally differentiating in this equilibrium condition, we obtain

$$
\frac{\partial p}{\partial z_{j}}=-\frac{\partial \sum_{l=1}^{n} m_{l} / \partial z_{j}}{\partial \sum_{l=1}^{n} m_{l} / \partial p}
$$

Now, since $U$ is homothetic and increasing, quasi-concave and in all its arguments, the domestic demand of commodity $X$ is

$$
x_{j}\left(P, G_{j}\right)=\alpha(P) \frac{G_{j}}{P}
$$

where $\alpha(P) \in(0,1)$. Also, country $j^{\prime} s$ output of commodity $X$ is $f\left(h_{j}, z_{j}\right)=$ $\frac{G_{i}}{P}$ if $j$ is specialized in commodity $X$, and 0 if $j<\hat{i}$. Thus,

$m_{j}=x_{j}-X_{j}=\left\{\begin{array}{cc}\alpha(P) \frac{G_{i}}{P}=\alpha(P) \frac{g\left(h_{j}, z_{j}\right)}{P} & \text { if } j<\widehat{i} \\ \alpha(P) \frac{G_{i}}{P}-\frac{G_{i}}{P}=f\left(h_{j}, z_{j}\right)(\alpha(P)-1) & \text { if } j \text { specialized in } X\end{array}\right.$ Notice that $\frac{\partial \sum_{l=1}^{n} m_{l}}{\partial p}<0$. Also, $\frac{\partial \sum_{l=1}^{n} m_{l}}{\partial z_{j}}=\frac{\partial m_{j}}{\partial z_{j}}$. Homogeneity of degree 1 of both $g$ and $f$, and decreasing returns in each of the inputs again allow us to conclude that $\frac{\partial p}{\partial z_{j}}>\frac{\partial p}{\partial z_{j^{\prime}}}>0$ for all $j<j^{\prime}<\widehat{i}$ and $\frac{\partial p}{\partial z_{j}}<\frac{\partial p}{\partial z_{j^{\prime}}}<0$ for all countries $j<j^{\prime}$ completely specialized in commodity $X$. Thus, the only thing that is left to analyze is $\frac{\partial m_{\hat{i}}}{\partial \widetilde{r}_{i}}$. For that purpose, we first show $\frac{h_{j}}{z_{j}} \leq \frac{h_{i}^{x}}{z_{i}^{x}}$ when $j$ is completely specialized in commodity $X$. That is, country $\widehat{i}$ produces commodity $X$ using $h$ more intensively than country $j$. Indeed, 
since $\hat{i}$ produces both commodities, and partial derivatives of the production function are homogeneous of degree 0 ,

$$
P \cdot \frac{\partial f\left(\frac{h^{x}}{z_{i}^{x}}, 1\right)}{\partial h}=\frac{\partial g\left(\frac{h_{i}^{y}}{z_{i}^{y}}, 1\right)}{\partial h} .
$$

Thus, if $\frac{h_{j}}{z_{j}}>\frac{h_{x}^{x}}{z_{i}^{x}}$, then

$$
P \cdot \frac{\partial f\left(\frac{h_{j}}{z_{j}}, 1\right)}{\partial h}<\frac{\partial g\left(\frac{h_{i}^{y}}{z_{i}^{y}}, 1\right)}{\partial h}
$$

so that country $j$ would increase its national income by switching an infinitesimal amount of inputs from the production of $X$ to the production of $Y$ in the proportion $\frac{h^{y}}{z^{y}}$.

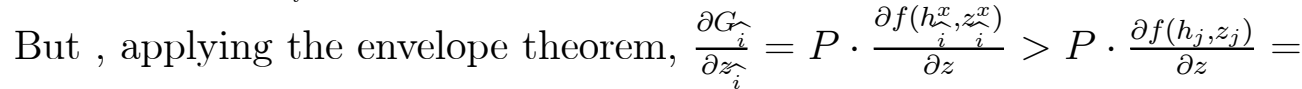
$\frac{\partial G_{j}}{\partial z_{j}}$. Thus, $m_{j}=f\left(h_{j}, z_{j}\right)(\alpha(P)-1)$, and $m_{\hat{i}}=\frac{G_{j}}{P} \alpha(P)-f\left(h_{i}^{x}, z_{i}^{x}\right)=$ $f\left(h_{i}^{x}, z_{i}^{x}\right)(\alpha(P)-1)+\frac{\alpha(P)}{P} g\left(h_{i}^{y}, z_{i}^{y}\right)$. Also, $\frac{\partial g\left(h_{i}^{y}(z), z_{i}^{y}(z)\right)}{\partial z}<0$, from Rybczynski's Theorem (where $h_{\hat{i}}^{y}(z)$ and $z_{i}^{y}(z)$ are quantities of inputs used in the production of $y$, as function of the total endowment of $z$ of country $\widehat{i}$ ). Thus, $\frac{\partial f\left(h_{i}^{x}(z), z_{i}^{x}(z)\right)}{\partial z}>\frac{\partial f\left(h_{i}^{x}, z_{i}^{x}\right)}{\partial z}$ (country $\hat{i}$ would not be maximizing national income otherwise), and since $\alpha(P)-1<0, \frac{\partial m_{\hat{i}}}{\partial z_{\hat{i}}}<\frac{\partial f\left(h_{i}^{x}, z_{i}^{x}\right)}{\partial z}(\alpha(P)-1)<\frac{\partial m_{j}}{\partial z_{j}}<0$. QED

Proposition 1: For $i^{*} \in I^{*},\left(m_{i^{*}}+m_{j}\right)\left(\frac{\partial p}{\partial z_{i^{*}}}-\frac{\partial p}{\partial z_{j}}\right) \leq 0$ for all $j \neq i^{*}$ if and only if $\hat{i}=1$. That is, if and only if country 1 produces both commodities.

Proof: First we proof the only if part. Assume that $\hat{i}>1$. If $\widehat{i}>2$, then $m_{1}+m_{2}>0$ and $\frac{\partial p}{\partial z_{1}}-\frac{\partial p}{\partial z_{2}}>0$ as well. Thus, we need consider only $\widehat{i}=2$. 
If $m_{2}>0$, again $m_{1}+m_{2}>0$ and $\frac{\partial p}{\partial z_{1}}-\frac{\partial p}{\partial z_{2}}>0$. If $m_{2}<0$, then for all $j>2$, we have that $m_{j}<0$ as well, from our remark 2 . Thus, only country 1 imports. Thus, we still have $m_{1}+m_{2}>0, \frac{\partial p}{\partial z_{i}^{*}}-\frac{\partial p}{\partial z_{2}}>0$.

Now we turn to the if part. Notice that if $i^{*}=1$, is the only country that is not specialized in the production of a single commodity, then country 1 is the only country that produces commodity $Y$ (the only country that imports $X)$ so that $m_{i^{*}}+m_{j}>0$ for all $j$. Also, $\frac{\partial p}{\partial z_{i^{*}}}<\frac{\partial p}{\partial z_{j}}<0$ for all $j$. Thus, $\left(m_{i^{*}}+m_{j}\right)\left(\frac{\partial p}{\partial z_{i^{*}}}-\frac{\partial p}{\partial z_{j}}\right) \leq 0$. QED.

Proposition 2: Assume that for $i^{*} \in I^{*},\left(m_{i^{*}}+m_{j}\right)\left(\frac{\partial p}{\partial z_{i^{*}}}-\frac{\partial p}{\partial z_{j}}\right) \leq 0$ for all $j \neq i^{*}$ (and then $\widehat{i}=1$ ). For any $j \notin I^{*}$ the gain from trading quota with $i^{*}$ is positive and larger that the gain from trading with any other country not in $I^{*}$.

Proof: We need to show that, under the assumptions of Lemma 1, $v_{i^{*}}+$ $e_{i^{*}}(j)-\left[v_{j}+e_{j}\left(i^{*}\right)\right]>v_{l}+e_{l}(j)-\left[v_{j}+e_{j}(l)\right]$ for all $j, l \notin I^{*}$. Notice that, if the assumption of Lemma 1 is satisfied, $v_{i^{*}}+e_{i^{*}}(j)>v_{l}+e_{l}(j)$. Thus, we need only showing that $e_{j}(l)>e_{j}\left(i^{*}\right)$. That is, $m_{j}\left(\frac{\partial p}{\partial z_{l}}-\frac{\partial p}{\partial z_{i^{*}}}\right)>0$. This follows from the assumption that $\widehat{i}=1$, which implies that all $j \notin I^{*}$ is specialized in the production of the dirty commodity so that $m_{j}<0$. QED. 